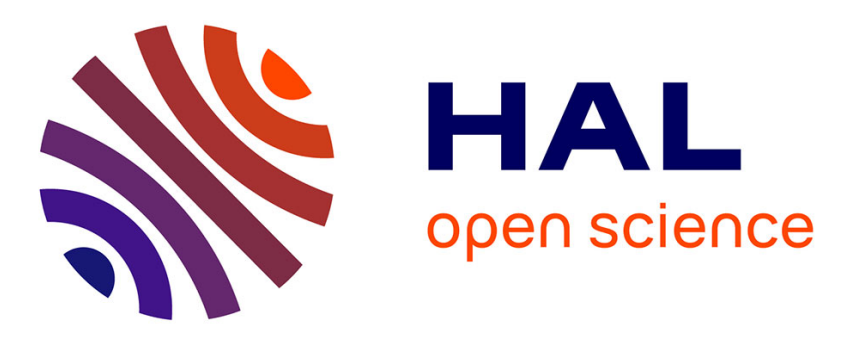

\title{
Highly fluorescent, color tunable and magnetic quaternary Ag-In-Mn-Zn-S quantum dots
}

Perizat Galiyeva, Halima Alem, Hervé Rinnert, Lavinia Balan, Sébastien Blanchard, Ghouti Medjahdi, Bolat Uralbekov, Raphael Schneider

\section{- To cite this version:}

Perizat Galiyeva, Halima Alem, Hervé Rinnert, Lavinia Balan, Sébastien Blanchard, et al.. Highly fluorescent, color tunable and magnetic quaternary $\mathrm{Ag}-\mathrm{In}-\mathrm{Mn}-\mathrm{Zn}-\mathrm{S}$ quantum dots. Inorganic Chemistry Frontiers, 2019, 6, pp.1422-1431. 10.1039/C9QI00131J . hal-02322146

\section{HAL Id: hal-02322146 \\ https://hal.science/hal-02322146}

Submitted on 6 Jan 2021

HAL is a multi-disciplinary open access archive for the deposit and dissemination of scientific research documents, whether they are published or not. The documents may come from teaching and research institutions in France or abroad, or from public or private research centers.
L'archive ouverte pluridisciplinaire HAL, est destinée au dépôt et à la diffusion de documents scientifiques de niveau recherche, publiés ou non, émanant des établissements d'enseignement et de recherche français ou étrangers, des laboratoires publics ou privés. 


\title{
Highly fluorescent, color tunable and magnetic quaternary Ag-In-Mn-Zn-S quantum dots
}

Perizat Galiyeva, ${ }^{\mathrm{a}}$ Halima Alem, ${ }^{\mathrm{b}}$ Hervé Rinnert, ${ }^{\mathrm{b}}$ Lavinia Balan, ${ }^{\mathrm{c}}$ Sébastien Blanchard, ${ }^{\mathrm{d}}$ Ghouti Medjahdi, ${ }^{b}$ Bolat Uralbekov ${ }^{\mathrm{e}}$ and Raphaël Schneider*a

a. Laboratoire Réactions et Génie des Procédés, Université de Lorraine, CNRS, LRGP, F-54000 Nancy, France.

b. Institut Jean Lamour, Université de Lorraine, CNRS, F-54506 Vandoeuvre-lès-Nancy, France. E-mail:raphael.schneider@univ-lorraine.fr

c. Institut de Science des Matériaux de Mulhouse (IS2M), CNRS, UMR 7361, 15 rue Jean Starcky, 68093 Mulhouse, France.

d. Sorbonne Université, CNRS, Institut Parisien de Chimie Moléculaire, IPCM, F-75005 Paris, France

e. Al-Farabi Kazakh National University, Al-Farabi Av., 71, Almaty 050040, Kazakhstan.

Electronic Supplementary Information (ESI) available. See DOI: 10.1039/C9QI00131J

\begin{abstract}
Mn-doped quantum dots (QDs) are of high interest for numerous applications like solar cells, optoelectronics, optosensing, or bioimaging. Here, we report the preparation of quaternary $\left(\mathrm{Ag} \operatorname{lnS} \mathrm{S}_{2}\right)_{x}(\mathrm{MnS})_{\mathrm{y}}(\mathrm{ZnS})_{1-\mathrm{x}-\mathrm{y}} \mathrm{QDS}$, thereafter noted Mn:AIZS via a thermally induced decomposition of $\mathrm{Ag}$, In, $\mathrm{Zn}$ and $\mathrm{Mn}$ precursors in the presence of oleylamine and dodecanethiol. The Mn:AIZS QDs have an average diameter of $3.5 \mathrm{~nm}$ and their XRD patterns can be indexed with the orthorhombic phase of AgInS ${ }_{2}$. The incorporation of $\mathrm{Mn}^{2+}$ ions in the AIZS crystal lattice results in a red-shift of the photoluminescence $(\mathrm{PL})$ emission maximum depending on the $\mathrm{Mn}^{2+}$ content. The PL quantum yields decrease upon loading with $\mathrm{Mn}^{2+}$ but remained high (53-31\%) until 50\% theoretical loading in $\mathrm{Mn}^{2+}$. Steady state, $\mathrm{PL}$ excitation and time-resolved $\mathrm{PL}$ measurements suggest that $\mathrm{Mn}^{2+}$-dependent trap states are involved in the PL emission. Mn:AIZS QDs exhibit also magnetic properties. In addition, Mn:AIZS QDs can easily be transferred to the aqueous phase using the PMAO amphiphilic polymer without alteration of their optical properties (PL quantum yield up to 51\%), revealing their high potential for biological applications.
\end{abstract}




\section{Introduction}

In recent years, I-III- $\mathrm{VI}_{2}$-based semiconductor quantum dots (QDs) like CulnS 2 (CIS) or AgInS 2 (AIS) and their I-II-III- $\mathrm{VI}_{2}$ alloys with $\mathrm{ZnS}$ (CIZS and AIZS, respectively) have gained high interest as alternatives to binary QDs like CdSe or CdTe because these nanocrystals are composed of weakly toxic elements and their optical properties can be controlled by varying their size and their composition. ${ }^{1-5}$ The bandgap of these QDs can be tuned from the visible to the near-infrared spectrum making them suitable for applications like photocatalysis, ${ }^{6,7}$ light-emitting diodes, ${ }^{8,9}$ solar cells, ${ }^{10}$ bio-imaging ${ }^{11,12}$ or bio-sensing. ${ }^{13-15}$ Although the fullwidth at half-maximum (fwhm) of the photoluminescence (PL) emission, and thus the color purity, of I-II-III- $\mathrm{VI}_{2}$ QDs is larger (ca. $100 \mathrm{~nm}$ ) than that of binary QDs like CdSe, these nanocrystals not only exhibit long PL lifetimes but also large Stokes shift between the absorption and the PL emission and thus do not suffer from self-absorption or non-radiative Förster resonance energy transfer.

For II-VI QDs, the PL emission usually originates from exciton recombination. For I-II-III- $\mathrm{VI}_{2}$ QDs, the PL emission mechanism is more complex and still under debate. ${ }^{16-21}$ Due to their heterogeneous composition, these dots contain high native defect densities which make their electronic band structures difficult to determine. For AIZS QDs, silver vacancies $\left(V_{a g}\right)$, sulfur vacancies $\left(V_{S}\right)$, silver interstitial atoms $\left(A g_{\text {int }}\right)$ and sulfur interstitial atoms $\left(S_{\text {int }}\right)$ have been reported and $V_{S}$ and $A g_{\text {int }}$ behave as donors while $V_{A g}$ and $S_{\text {int }}$ as acceptors. ${ }^{17,22,23}$ Therefore, the recombination of carriers trapped by intragap levels originating from surface defects, also called donor-acceptor (D-A) pair recombination, markedly contributes to the PL emission. The PL emission of AIZS QDs was demonstrated to exhibit two components: (1) a fast transition with a PL lifetime of ca 25 ns originating from a delocalized valence/conduction band transition and (2) a slower component (PL lifetime higher than 185 ns) originating from the deep D-A pair transition, its contribution being dependent on the composition of the nanocrystals. ${ }^{18}$

The incorporation of transition metal cations like $\mathrm{Mn}^{2+}$ in QDs allows not only to confer to these nanocrystals new properties like magnetism but also to tune their optical properties. To date, the doping of CIZS or AIZS QDs with $\mathrm{Mn}^{2+}$ ions has only scarcely been investigated. When using a low amount of $\mathrm{Mn}^{2+}$ and a high level of $\mathrm{Zn}^{2+}$ ions in CIZS or AIZS QDs, the D-A emission was suppressed and only the $\mathrm{PL}$ emission originating from the $\mathrm{Mn}^{2+}{ }^{4} \mathrm{~T}_{1} \rightarrow{ }^{6} \mathrm{~A}_{1}$ 
transition located at ca. $600 \mathrm{~nm}$ was observed. ${ }^{24,25}$ The temperature-dependent PL properties of $\mathrm{Mn}$-doped CIZS was also demonstrated. ${ }^{26}$ When $\mathrm{Mn}^{2+}$ were adsorbed at the periphery of the CIS cores followed by the ZnS shell coating and the alloying, the obtained nanocrystals exhibited both the $\mathrm{Mn}^{2+}$ and the $\mathrm{D}-\mathrm{A}$ pair emissions. ${ }^{27}$

In this paper, we report the incorporation of $\mathrm{Mn}^{2+}$ ions in green- or orange-emitting AIZS QDs via a one-pot reaction conducted in oleylamine (OAm). The loading in $\mathrm{Mn}^{2+}$ was varied from 25 to $75 \%$ relative to the total amount of metal cations in the dots to prepare quaternary $\left.(\mathrm{AgInS})_{2}\right)_{x}(\mathrm{MnS})_{\mathrm{y}}(\mathrm{ZnS})_{1-\mathrm{x}-\mathrm{y}} \mathrm{QDs}$, thereafter noted Mn:AIZS. Our results show that the PL emission of Mn:AIZS QDs, originating from the D-A pair recombination, can be tuned by varying the $\mathrm{Mn}^{2+}$ content of the dots. Time-resolved $\mathrm{PL}$ was used to investigate the PL behaviors of $\mathrm{Mn}$ :AIZS QDs at different $\mathrm{Mn}^{2+}$ loadings. The small sized, highly fluorescent and magnetic Mn:AIZS QDs can easily be transferred in aqueous solution using poly(maleic anhydride-alt-1-octadecene) (PMAO) and are therefore of high potential for bio-imaging or cells labeling and sorting.

\section{Results and discussion}

\section{Morphology and structure characterization}

Mn:AIZS QDs were prepared via a one-pot synthetic protocol developed for AIZS $\mathrm{QDs}^{6}{ }^{6}$ in which $\mathrm{AgOAc}, \operatorname{In}(\mathrm{OAc})_{3}, \mathrm{Zn}(\mathrm{OAc})_{2}$ and manganese stearate $\left(\mathrm{Mn}(\mathrm{St})_{2}\right)$ and thiourea precursors were thermally decomposed in the presence of a mixture of dodecanethiol (DDT) and OAm used as capping ligands. Green and orange-emitting AIZS QDs were prepared using $\mathrm{Ag} / \mathrm{In} / \mathrm{Zn}$ molar ratios of 0.02/0.02/0.16 and $0.06 / 0.06 / 0.08$, respectively. The amount of DDT used to control the size of the nanocrystals was fixed at $2 \mathrm{~mol} \%$ and the loading of $\mathrm{Mn}(\mathrm{St})_{2}$ was varied $(25,50$ or 75 mol\% relative to the total amount of salts in the reaction medium). Further increasing the loading in $\mathrm{Mn}(\mathrm{St})_{2}$ was found to be deleterious on the QDs optical properties (vide infra). In preliminary experiments, we observed that after complete dissolution of the precursors at room temperature, the optimal optical properties were obtained when heating the reaction mixture at $180^{\circ} \mathrm{C}$ and this temperature was kept in further experiments. The reaction mixture was maintained at $180^{\circ} \mathrm{C}$ for $10 \mathrm{~min}$ before cooling 
to room temperature and purification of the QDs. Only weak shifts of the UV-visible absorption and of the PL emission to lower energy were observed during the $10 \mathrm{~min}$ of heating indicating that no significant growth of the nanocrystals occurred during that period.

Fig. 1 and S1 show X-ray diffraction (XRD) patterns of orange- and green-emitting AIZS and $\mathrm{Mn}: \mathrm{AIZS}$ QDs, respectively. The broadness of the peaks is indicative of the small size of the nanocrystals. The peaks located at 25.4, 26.8, 28.8, 37.4, 44.9, 48.8 and $53.2^{\circ}$ correspond to the (120), (002), (121), (122), (320), (123) and (322) planes of the AIS orthorhombic structure, respectively (JCPDS card No 25-1328, Pna $2_{1}$ space group, $\mathrm{a}=0.7008 \mathrm{~nm}, \mathrm{~b}=0.8162 \mathrm{~nm}$ and $\mathrm{c}=0.6585 \mathrm{~nm}$ ), as demonstrated by the Rietveld refinements using the Fundamental Parameters approach built in the Topas application (Bruker XAS) shown in Fig. S2. These results are in accordance with the synthetic method used. ${ }^{6}$ The orthorhombic phase is stable above $620^{\circ} \mathrm{C}$ while the tetragonal chalcopyrite structure is stable below $620^{\circ} \mathrm{C}{ }^{2}$ This phase reversion likely originates from the use of OAm as solvent which modifies the chemical growth environment of the nanocrystals. ${ }^{2}$ The peaks are shifted towards larger angles compared to pure AIS crystals, due to the diffusion of $\mathrm{Zn}^{2+}$ and $\mathrm{Mn}^{2+}$ ions into the AIS core which conducts to a lattice shrinkage as the ion radii of $\mathrm{Zn}^{2+}(0.075 \mathrm{~nm})$ and $\mathrm{Mn}^{2+}$ $(0.070 \mathrm{~nm})$ are smaller than that of $\mathrm{In}^{3+}(0.094 \mathrm{~nm})$ and $\mathrm{Ag}^{+}(0.115 \mathrm{~nm})$. No significant shift of XRD peaks was observed when varying the $\mathrm{Mn}^{2+}$ loading, indicating that $\mathrm{Mn}^{2+}$ ions were incorporated in the QDs without significant changes in their crystal structure. Finally, no impurity like $\mathrm{Ag}_{2} \mathrm{~S}, \mathrm{In}_{2} \mathrm{~S}_{3}$ or $\mathrm{MnS}$ was detected indicating that phase separation did not occur even using a high loading in $\mathrm{Mn}^{2+}$. 


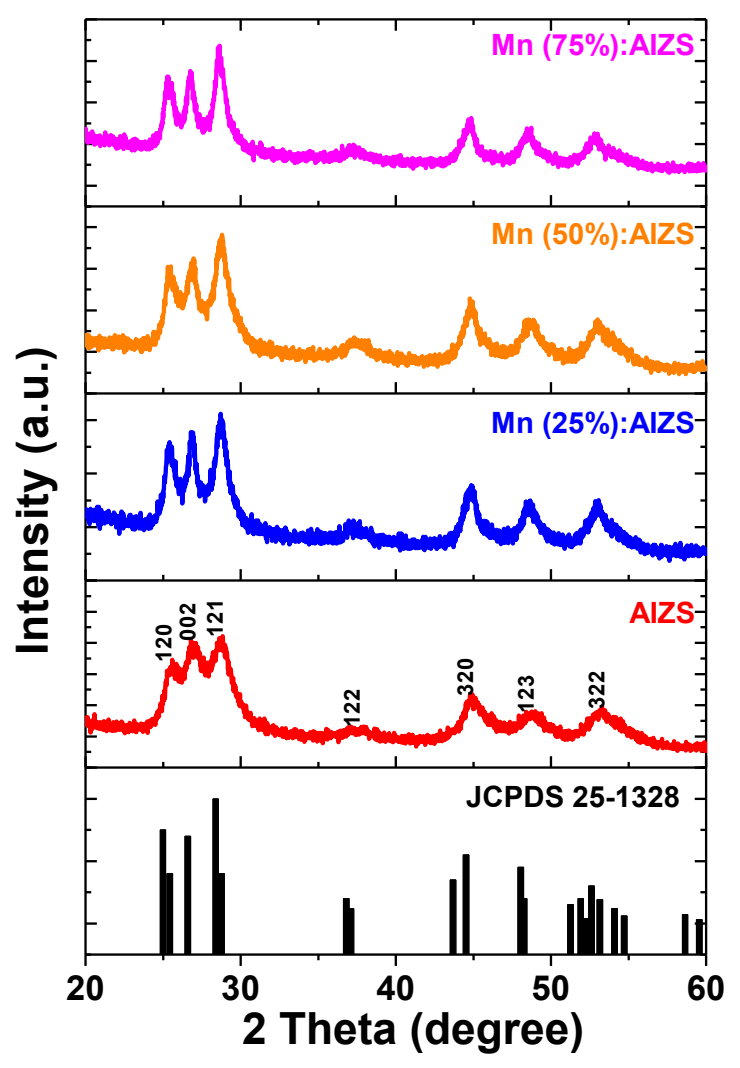

Fig. 1 XRD patterns of red-emitting AIZS and Mn:AIZS QDs when varying the $\mathrm{Mn}^{2+}$ loading.

Both energy-dispersive X-ray (EDX) and inductively coupled plasma-optical emission spectrometer (ICP-OES) analyses confirm the presence of $\mathrm{Zn}, \mathrm{Ag}, \mathrm{In}, \mathrm{Mn}$ and $\mathrm{S}$ elements in Mn:AIZS QDs but the stoichiometry is different from that used for the synthesis (see Table 1 for ICP-OES results where the actual ratios of $\mathrm{Ag} / \mathrm{In} / \mathrm{Mn} / \mathrm{Zn}$ are normalized to the molar amount of the Ag element and Fig. S3 and Table S1 for EDX results). According to EDX and ICP-OES analyses, the QDs have a non-stoichiometric composition with an excess of $S$ compared to metal ions and a defect in Ag compared to In and $\mathrm{Zn}$. The high amount of S detected originates from the presence of $S$ both in the core and in the DDT capping ligand. While equimolar amounts of $\mathrm{Ag}$ and In were charged in the reaction flask, AIZS QDs obtained after purification appear significantly richer in the In element (In/Ag atomic ratio of 1.54). Although $\operatorname{In}^{3+}$ is a hard Lewis acid according to the Pearson theory while $\mathrm{Ag}^{+}$and $\mathrm{S}^{2-}$ exhibit a soft character, this result may be related to the difference of chemical reactivity of $\mathrm{Ag}$ and In precursors towards $\mathrm{S}^{2-}$ in the reaction solution. When $\mathrm{Mn}^{2+}$ was loaded in the AIZS nanocrystals, the contents in $\mathrm{Ag}^{+}$and $\mathrm{In}^{3+}$ of the QDs decrease while that of $\mathrm{Zn}^{2+}$ remains 
almost constant, suggesting that a cation exchange allowing the replacement of $\mathrm{Ag}^{+}$and $\mathrm{In}^{3+}$ by $\mathrm{Mn}^{2+}$ occurs. Finally, EDX analyses show that the amount of $\mathrm{Mn}^{2+}$ ions loaded in the nanocrystals is significantly lower that the amount used for the synthesis $(1.82,5.37$ and 11.89 at.\% of $\mathrm{Mn}^{2+}$ were detected when using 25, 50 and $75 \%$ of $\mathrm{Mn}^{2+}$ relative to the total amount of metallic salts used for the synthesis), suggesting that $\mathrm{Mn}^{2+}$ ions poorly incorporate into the AIZS crystal lattice.

Table 1. Theoretical and actual $\mathrm{Ag} / \mathrm{In} / \mathrm{Mn} / \mathrm{Zn}$ ratios determined by ICP-OES for orangeemitting AIZS QDs when varying the $\mathrm{Mn}^{2+}$ loading

\begin{tabular}{ccc}
\hline QDs & $\begin{array}{c}\mathrm{Ag} / \mathrm{In} / \mathrm{Mn} / \mathrm{Zn} \text { ratio in } \\
\text { precursors }\end{array}$ & $\begin{array}{c}\text { Actual ratios of } \\
\mathrm{Ag} / \mathrm{ln} / \mathrm{Mn} / \mathrm{Zn}\end{array}$ \\
\hline AIZS & $1 / 1 / 0 / 1.33$ & $1 / 1.54 / 0 / 1.80$ \\
Mn (25\%):AIZS & $1 / 1 / 0.83 / 1.33$ & $1 / 1.55 / 0.17 / 1.97$ \\
Mn (50\%):AIZS & $1 / 1 / 1.66 / 1.33$ & $1 / 1.62 / 0.55 / 2.02$ \\
Mn (75\%):AIZS & $1 / 1 / 2.5 / 1.33$ & $1 / 1.47 / 1.44 / 2.38$ \\
\hline
\end{tabular}

Low temperature $(20 \mathrm{~K}) \mathrm{X}$-band electron paramagnetic resonance (EPR) spectra recorded on the Mn:AIZS QDs further support the loading of $\mathrm{Mn}^{2+}$ in the nanocrystals. In all cases, a broad signal centered on $\mathrm{g}=2$ is detected. The broadness of the signal is typical for $\mathrm{Mn}$ doped AIZS or CIZS QDs and originates from the complex environment of $\mathrm{Mn}^{2+}$ surrounded by $\mathrm{Ag}^{+}, \mathrm{In}^{3+}$ and $\mathrm{Zn}^{2+}$ ions. ${ }^{24}$ While poorly resolved hyperfine coupling can be observed for $50 \%$ and $75 \%$ loading in $\mathrm{Mn}^{2+}$, the spectrum of the $\mathrm{Mn}$ (25\%):AIZS QDs displays a set of six lines separated by about $80 \mathrm{G}$, which is related to the coupling of the electronic spin with the $5 / 2$ nuclear spin of $\mathrm{Mn}^{2+}$. 


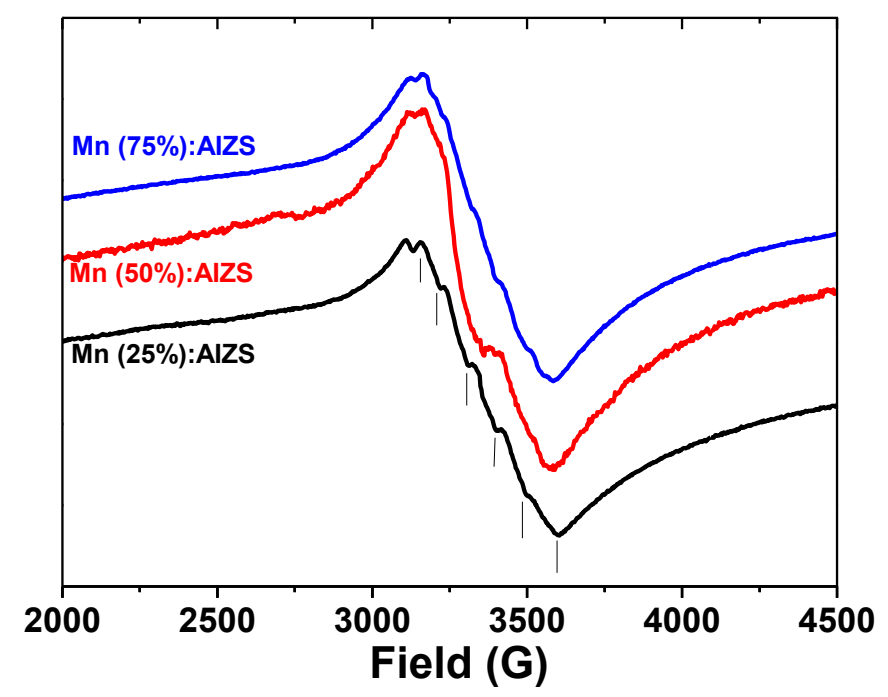

Fig. 2 EPR spectra recorded at $20 \mathrm{~K}$ of orange-emitting AIZS loaded with 25, 50 and 75\% $\mathrm{Mn}^{2+}$.

Transmission Electron Microscopy (TEM) and High-Resolution TEM (HR-TEM) were used to characterize the size and the shape of AIZS and Mn:AIZS QDs. Fig. 3 shows the results obtained with orange-emitting AIZS QDs when increasing the loading percentage in $\mathrm{Mn}^{2+}$ from 25 to $75 \%$. The average size of the nanocrystals was determined by analyzing at least 100 nanocrystals in the TEM images and, regardless of the Mn-loading percentage, was found to vary between 3.3 and $3.7 \mathrm{~nm}$ (see Fig. S4 for the size distributions). Mn:AIZS QDs shape is irregular and spherical, ellipsoidal and triangular particles can be observed in each sample. The clear lattice fringes in the associated HR-TEM images confirm that Mn:AIZS QDs are single crystals. The lattice space measured is of ca. $0.35 \mathrm{~nm}$ and corresponds to the (120) crystal plane of orthorhombic AgInS 2 . The high crystallinity of the dots is further evidenced from the selected area electron diffraction (SAED) patterns (insets of Fig. 3) which show a set of concentric rings corresponding to the diffraction of the various crystalline planes of the nanocrystals. 

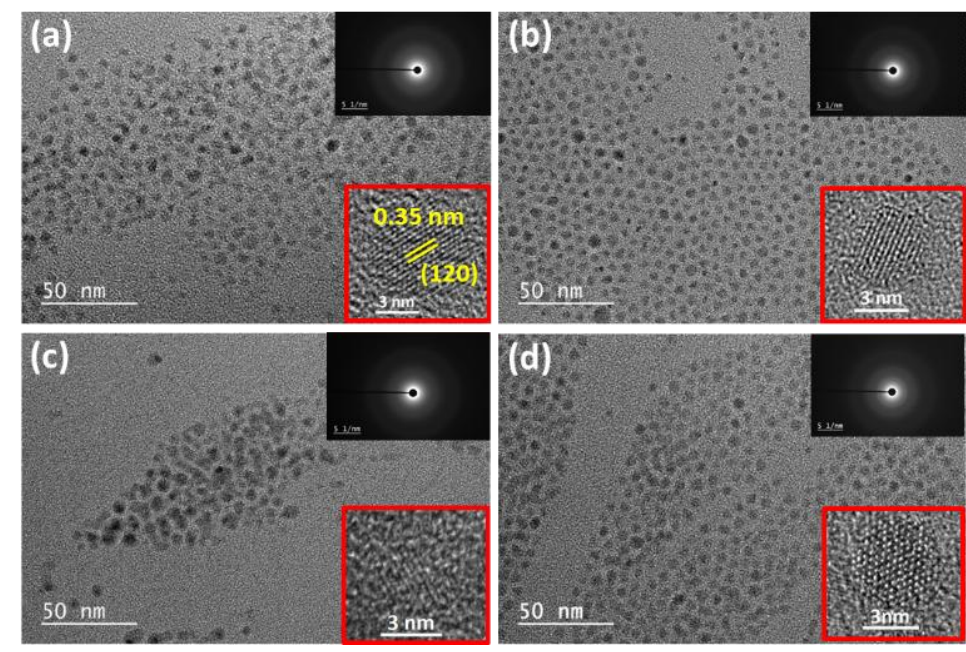

Fig. 3 TEM and HR-TEM images of (a) orange-emitting AIZS and (b-d) Mn:AIZS QDs loaded with 25,50 and $75 \% \mathrm{Mn}^{2+}$, respectively. The insets shows SAED patterns.

A representative thermogravimetric analysis (TGA) of the $\mathrm{Mn}$ (50\%):AIZS QDs is given in Fig. 4a and shows three mass loss regions. The two first mass losses (between 250$350^{\circ} \mathrm{C}$ and $360-460^{\circ} \mathrm{C}$ ) likely originates from the removal of neutral ligand (DDT and OAm) anchored at the surface of the dots while the third weight loss might originate from the removal of ionic ligand (DDT covalently bound to surface $\mathrm{Zn}$ atoms). The remaining mass (ca. 73\%) corresponds to the inorganic Mn:AIZS core and indicates that the QDs are covered by a relatively thick shell of ligands. The presence of the DTT and OAm ligands at the periphery of the dots was further confirmed by FT-IR. The symmetric and antisymmetric $\mathrm{C}-\mathrm{H}$ stretching of methylene groups of OAm and DDT can be observed at 2916 and $2850 \mathrm{~cm}^{-1}$, respectively, while the in-plane deformation of these bonds can be observed at $1453 \mathrm{~cm}^{-1}$. The weak signal at $3002 \mathrm{~cm}^{-1}$ is characteristic of the ethylenic $\mathrm{C}-\mathrm{H}$ stretching of $\mathrm{OAm}$. The $\mathrm{N}-\mathrm{H}$ stretching and bending appear at 3209 and $1614 \mathrm{~cm}^{-1}$, respectively. The C-S stretching of DDT at $1375 \mathrm{~cm}^{-1}$ further confirms the co-capping of the dots with OAm and DDT. 

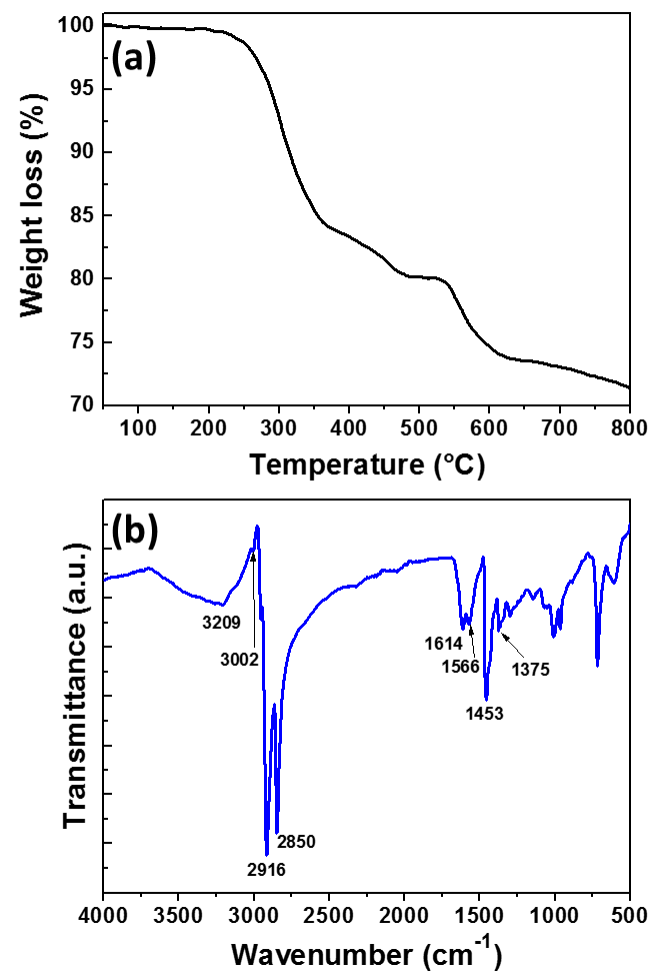

Fig. 4. (a) TGA trace and (b) FT-IR spectrum of Mn (50\%):AIZS QDs.

\section{Optical properties}

Fig. 5 shows the UV-vis absorption and the PL emission spectra of green- and orangeemitting AIZS QDs and the evolution of these spectra when increasing the loading in $\mathrm{Mn}^{2+}$ from 25 to $75 \%$. All spectra were recorded using nanocrystals obtained after 10 min heating at $180^{\circ} \mathrm{C}$ and purified by precipitation and washing with methanol. The broad absorption without a marked exciton band is typical of ternary like AIS and quaternary like AIZS QDs and originates from the distribution of vibrational states rather than from size and/or composition inhomogeneity of the dots. ${ }^{1,2,28}$ A slight shift to lower energies is observed when increasing the loading in $\mathrm{Mn}^{2+}$, which suggests a decrease of the bandgap and thus a modification of the electronic states of the AIZS core. The shift to lower energies may be caused by the lattice shrinkage originating from the diffusion of $\mathrm{Mn}^{2+}$ ions in the AIZS core as previously show by XRD experiments. The incorporation of $\mathrm{Mn}^{2+}$ ions in the AIZS core may also generate additional sub-bandgap transitions that may contribute to the tail absorption (vide infra). The bandgap values were determined from the Tauc plots of $(\alpha h v)^{2}$ vs hv (where $\alpha$ is the absorption coefficient and hv is the photon energy) and were found to 
decrease from 2.52 to 2.31 and from 2.93 to $2.83 \mathrm{eV}$ for orange- and green-emitting AIZS QDs, respectively, when loading these nanocrystals with 25,50 and $75 \% \mathrm{Mn}^{2+}$ (Fig. 6). These values are higher than that of bulk $\mathrm{AgInS}_{2}$ in orthorhombic phase $(1.87 \mathrm{eV})$ due to the quantum confinement effect in AIZS and Mn:AIZS QDs. The steady state PL emission spectra or green- and orange emitting AIZS QDs are broad and their fwhm are of ca. 100 and 138 $\mathrm{nm}$, respectively (Fig. 5a-b). The maximum of the PL peaks are located at 540 and $660 \mathrm{~nm}$ and the PL QYs are 46 and 62\% for the green and the orange-emitting QDs, respectively. As previously mentioned, the broadness and the asymmetry of the spectra originate from the numerous D-A transitions and trap-state emissions in these nanocrystals. ${ }^{16-21}$ For both QDs, a marked Stokes shift is observed, indicating that the self-absorption is minimal and further corroborating that the PL emission is not a bandgap emission.
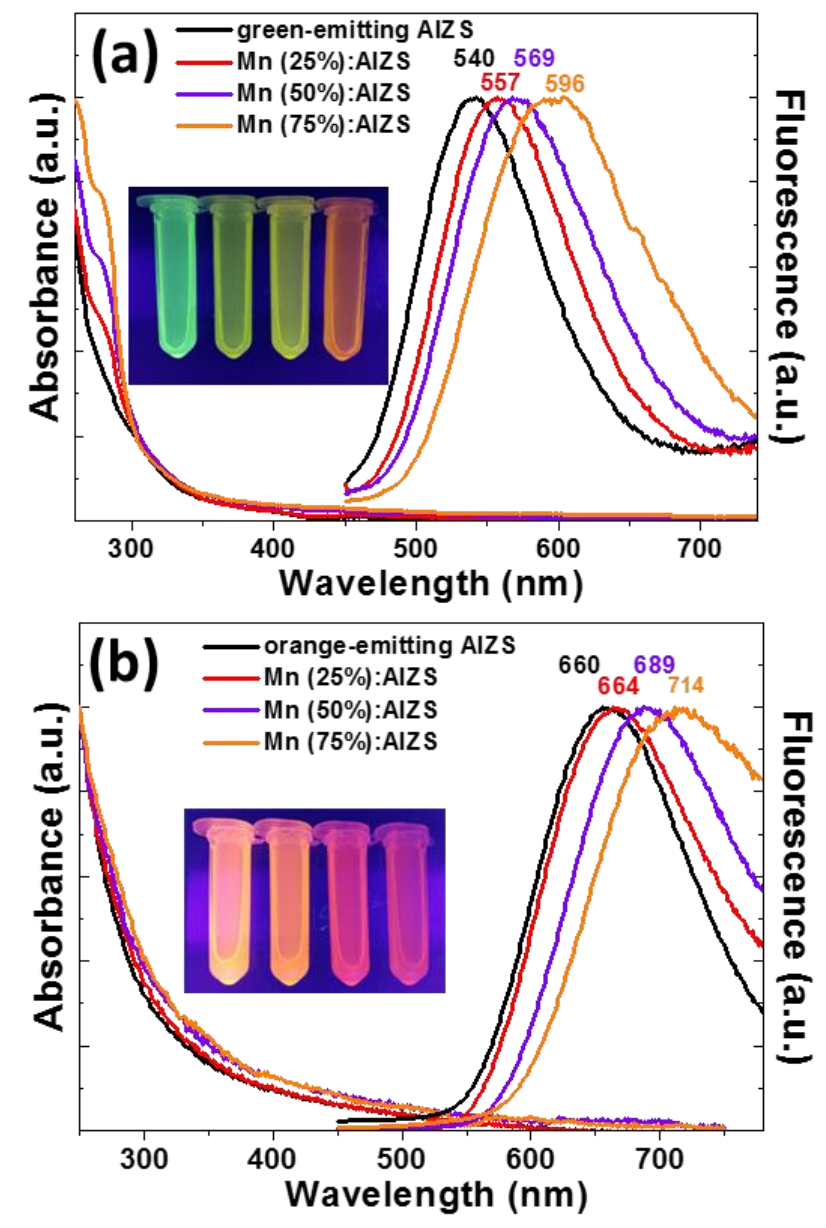

Fig. 5 UV-visible absorption and normalized PL emission spectra of (a) green and (b) orange emitting QDs when increasing the $\mathrm{Mn}^{2+}$ loading from 25 to $75 \%\left(\lambda_{\mathrm{ex}}=400 \mathrm{~nm}\right)$. The insets are digital photographs of the dots dispersed in chloroform under UV light illumination. 
When loading these AIZS QDs with $\mathrm{Mn}^{2+}$, a continuous red-shift from 540 to $596 \mathrm{~nm}$ and from 660 to $714 \mathrm{~nm}$ is observed compared to green- and orange-emitting QDs, respectively, indicating that $\mathrm{Mn}^{2+}$ ions contribute to the $\mathrm{PL}$ emission mechanism. However, contrary to previous reports describing the preparation of $\mathrm{Mn}$-doped AIZS QDs, the ${ }^{4} \mathrm{~T}_{1} \rightarrow{ }^{6} \mathrm{~A}_{1}$ emission of $\mathrm{Mn}^{2+}$ ions in the AIZS host was not observed at ca. 600 $\mathrm{nm}$, which suggest that $\mathrm{Mn}^{2+}$ ions incorporated in AIZS QDs via the synthetic method developed in this work do not quench the D-A pair emission. ${ }^{24,25} \mathrm{PL}$ excitation (PLE) spectra of AIZS and Mn (25\%):AIZS QDs are shown in Fig. S5. A broad signal with a maximum located at ca. $520 \mathrm{~nm}$ was observed for both QDs, which is in good agreement with previously described PLE spectra of AIZS QDs emitting in red region. ${ }^{13,19}$ PLE have been also measured (not shown here) for an emission from 550 $\mathrm{nm}$ to $900 \mathrm{~nm}$ with a step equal to $4 \mathrm{~nm}$ for AIZS and Mn:AIZS and the spectra show the same shape. The similar profiles confirm that the $\mathrm{Mn}^{2+}$-related ${ }^{4} \mathrm{~T}_{1} \rightarrow{ }^{6} \mathrm{~A}_{1}$ transition is not involved in the PL excitation and emission of Mn:AIZS QDs. We assume that the PL red-shift observed when increasing the dopant loading likely originates from the $\mathrm{Mn}^{2+}$ position in the AIZS host and thus from the synthetic method used.

The PL shifts do not originate from a size increase of the dots as indicated by TEM (Fig. 3 and S4) but rather from a decrease of the bandgap as previously demonstrated. Simultaneously, their shape was also found to be dependent on the $\mathrm{Mn}^{2+}$ loading and the fwhm of the PL peak increases up to 144 and $170 \mathrm{~nm}$ for Mn:AIZS QDs emitting at 596 and $714 \mathrm{~nm}$, respectively, while it should be of ca. 60 $\mathrm{nm}$ for the $\mathrm{Mn}$ d-state emission. ${ }^{24}$ The PL intensity of Mn:AIZS QDs remains high but a continuous decrease of the PL QY is observed when increasing the $\mathrm{Mn}^{2+}$ content. For green-emitting AIZS, the PL QY decreases from 46 to 38,31 and 13\% for theoretical loadings in $\mathrm{Mn}^{2+}$ of 25,50 and $75 \%$. A similar behavior is observed starting from orange-emitting QDs (decrease from 62 to 53, 41 and 16\%, respectively). 

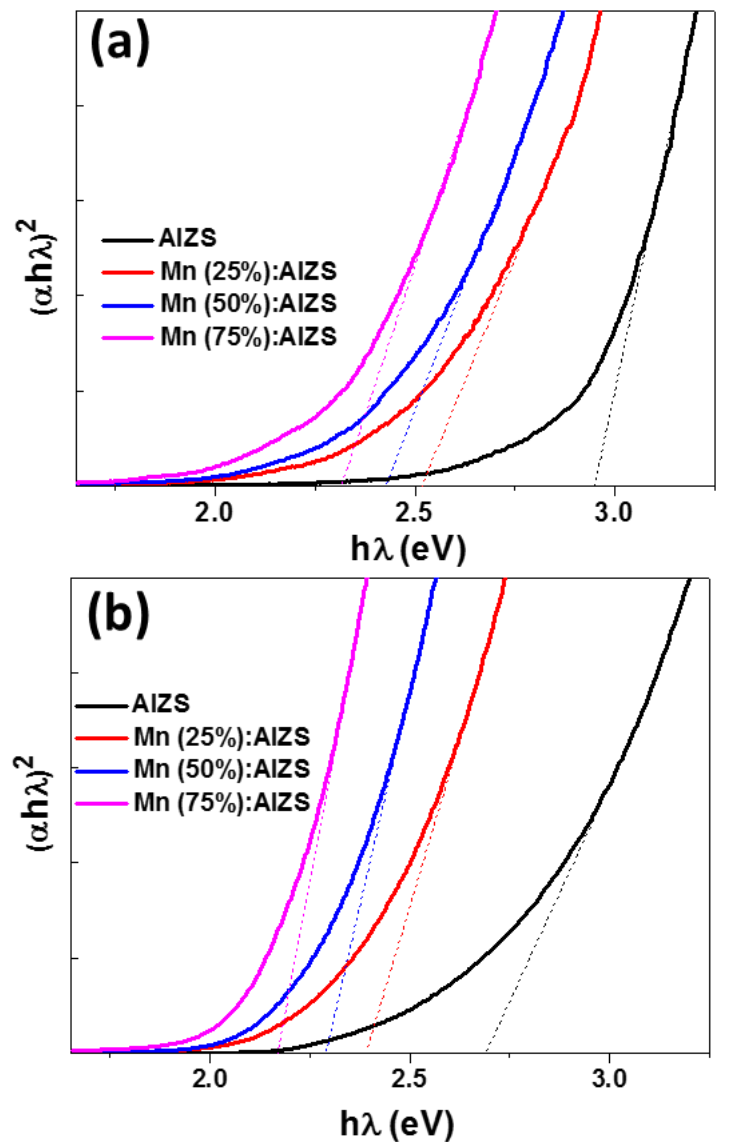

Fig. 6 Determination of the optical bandgap of AIZS and Mn:AIZS QDs when increasing the loading in $\mathrm{Mn}^{2+}$ ions in (a) green-emitting AIZS QDs and (b) orange-emitting AIZS QDs.

The PL mechanism for AIZS QDs is presented schematically in Fig. 7a and shows the radiative D-A pair recombination. On the basis of the previously described results, the position of the trap state $A$ relative to the $\mathrm{Mn}^{2+}{ }^{6} \mathrm{~A}_{1}$ state determines the recombination process. ${ }^{16-21,24}$ If the trap state $A$ is located below the $\mathrm{Mn}^{2+}{ }^{6} \mathrm{~A}_{1}$ state, the typical ${ }^{4} \mathrm{~T}_{1} \rightarrow{ }^{6} \mathrm{~A}_{1}$ transition of $\mathrm{Mn}^{2+}$ yielding an orange $\mathrm{PL}$ at ca. $600 \mathrm{~nm}$ should be observed (Fig. 7b). ${ }^{24}$ The dependence of the PL emission peak with the $\mathrm{Mn}^{2+}$ content suggests that a new $\mathrm{Mn}^{2+}$ dependent trap state located above the ${ }^{6} \mathrm{~A}_{1}$ state and with a gradually higher energy appears while increasing the $\mathrm{Mn}^{2+}$ loading of AIZS QDs as demonstrated by the continuous red-shift of the PL peak with the increase of the $\mathrm{Mn}^{2+}$ content (Fig. 7c). 

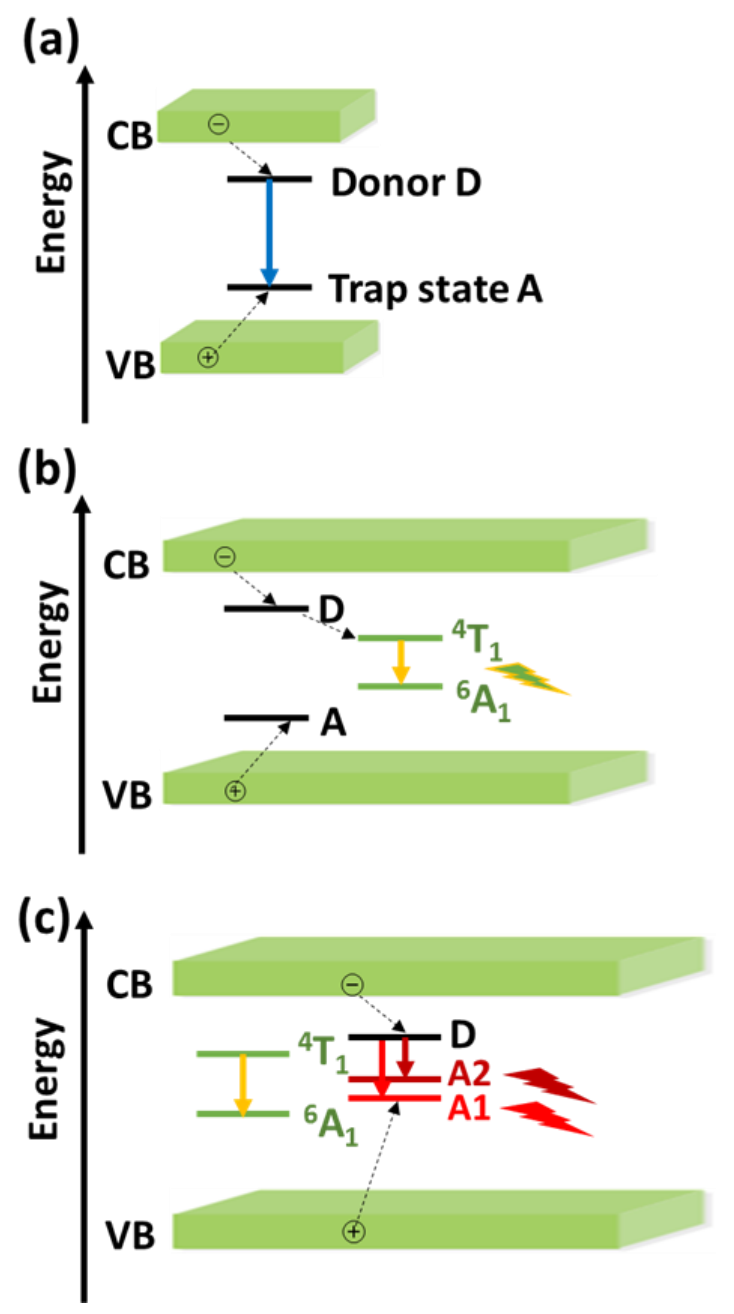

Fig. 7 Schematic illustration of the PL mechanism of (a) AIZS and (b-c) Mn:AIZS QDs. The solid arrows correspond to radiative relations while the dotted arrows show the non-radiative relaxations.

To further study the mechanism of the PL emission, time-resolved PL decay measurements were carried out. Representative time-resolved PL decay spectra were recorded at the $\mathrm{PL}$ emission maxima of orange-emitting AIZS and $\mathrm{Mn}$ :AIZS QDs obtained from Fig. 5a and results are shown in Fig. 8. The data were best fitted using a bi-exponential function $I(t)=A_{1} \exp \left(-t / \tau_{1}\right)$ and $A_{2} \exp \left(-t / \tau_{2}\right)$ where $\tau_{1}$ and $\tau_{2}$ are the time constants of the $P L$ and $A_{1}$ and $A_{2}$ the normalized amplitudes of the components. The fitting parameters are summarized in Table 2 . The average PL lifetimes $\left(\tau_{\mathrm{av}}\right)$ were determined using $\tau_{a v}=\left(A_{1} \tau_{1}+A_{2} \tau_{2}\right) /\left(A_{1}+A_{2}\right)$ and are in the typical range of 1 to $10 \mu \mathrm{s}^{-}$ ${ }^{1}$ generally observed for AIZS nanocrystals due to the numerous intrinsic trap states $\left(V_{S}\right.$ and $A_{\text {int }}$ acting as donors while $V_{A g}$ and $S_{\text {int }}$ as acceptors). ${ }^{11,16-21,29}$ These results 
further confirm that the PL emission does not originate from $\mathrm{Mn}^{2+}$ ions which exhibits a millisecond PL lifetime. ${ }^{30,31}$

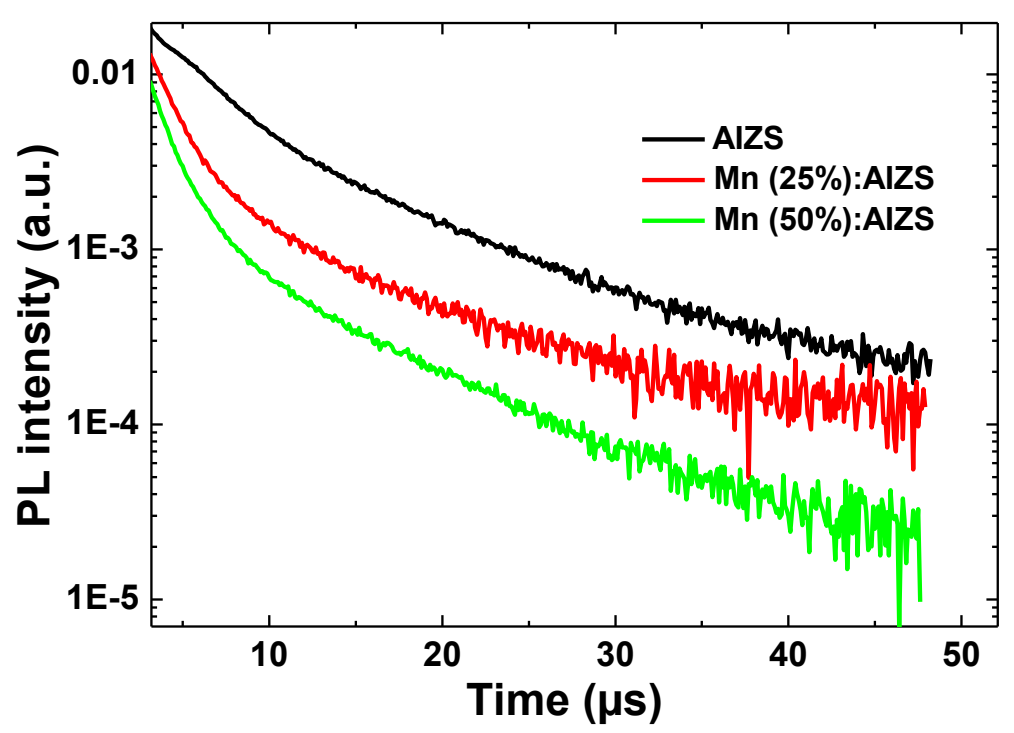

Fig. 8 PL lifetimes of orange-emitting AIZS and of the corresponding Mn:AIZS QDs at the PL maximum wavelength.

Table 2 Lifetimes and fitting parameters of orange-emitting AIZS and Mn:AIZS nanocrystals

\begin{tabular}{|c|c|c|c|c|c|}
\hline Sample & $\begin{array}{l}A_{1} \\
(\%)\end{array}$ & $\begin{array}{c}\tau_{1} \\
(\mu \mathrm{s})\end{array}$ & $\begin{array}{l}\mathrm{A}_{2} \\
\text { (\%) }\end{array}$ & $\begin{array}{c}\tau_{2} \\
(\mu \mathrm{s})\end{array}$ & $\begin{array}{c}\tau_{\mathrm{av}} \\
(\mu \mathrm{s})\end{array}$ \\
\hline AIZS & 54.1 & 2.738 & 45.9 & 10.143 & 6.14 \\
\hline $\mathrm{Mn}(25 \%): A I Z S$ & 75.8 & 1.471 & 24.2 & 8.146 & 3.09 \\
\hline $\mathrm{Mn}(50 \%): \mathrm{AIZS}$ & 87.8 & 1.344 & 12.2 & 7.832 & 2.14 \\
\hline
\end{tabular}

These long PL lifetimes clearly differentiate AIZS QDs from binary QDs like CdSe or CdTe that exhibit a short PL lifetime of tens of nanoseconds originating from band to band emission. ${ }^{32}$ As previously described, two radiative channels were observed. ${ }^{33}$ The fast decay component $\tau_{1}$ corresponds to surface trap state recombination and the slow decay component $\tau_{2}$ to the D-A recombination originating from the defect states within the bandgap. Until 50\% loading in $\mathrm{Mn}^{2+}$, which corresponds to the dots with a $\mathrm{PL}$ QY only weakly affected by the $\mathrm{Mn}^{2+}$ incorporation (vide supra), a decrease of the 
decay time of both components is observed. This decrease is however more pronounced for the fast component, suggesting a more pronounced influence of $\mathrm{Mn}^{2+}$ ions on the surface-related states. Moreover, its amplitude $A_{1}$ increases, indicating that the observed evolution of the time-resolved PL can be interpreted by the promotion of energy migration from $\mathrm{Mn}^{2+}$ to the surface quench centers as observed in previous studies. ${ }^{27}$

\section{Magnetic properties}

AIZS QDs do not display any magnetic response with the applied field. When $\mathrm{Mn}^{2+}$ is incorporated within the nanocrystals, and regardless of the loading percentage, the magnetic moment $(M)$ is the merge of a ferromagnetic signal (evident from the hysteresis at low fields in the inset of Fig. 9b,d and f) and of a paramagnetic and/or superparamagnetic signal (evident from the overall Langevin-like shape of the curves at high fields). Previous works demonstrated that nanocrystals doped with $\mathrm{Mn}^{2+}$ display a ferromagnetic behavior ${ }^{34-}$ ${ }^{38}$ whereas the $\mathrm{Mn}^{2+}$ ions are well known to be paramagnetic. ${ }^{39,40}$ The coercivity $H_{c}$ (the applied field required for zero net moment) and the remanence $M_{r}$ (the magnetic moment at zero applied field) can both be trivially extracted from the hysteresis loops (Fig. 9b and d). The samples synthesized at high concentration of $\mathrm{Mn}^{2+}$ exhibit the highest saturation magnetization, up to $0.25 \mathrm{emu} / \mathrm{g}$ (at $10 \mathrm{~K}$ ) (Fig. 9a), and decrease above $0.02 \mathrm{emu} / \mathrm{g}$ at room temperature. The decrease of the amount of $\mathrm{Mn}^{2+}$ leads to the decrease of $\mathrm{Ms}$ values below $0.17 \mathrm{emu} / \mathrm{g}$, and the temperature dependence is drastically increased. All Mn:AIZS QDs exhibit remanent magnetization (Fig. 9a and c), up to $0.001 \mathrm{emu} / \mathrm{g}$ at $10 \mathrm{~K}$. Fig. 9e depicts the behavior of the Mn (25\%):AIZS doped sample, no influence of the temperature on the magnetic behavior of the QDs can be evidenced. The extraction of saturation magnetization $\left(M_{s}\right)$ from the curves is non-trivial, since saturation was not achieved in the system due to persisting paramagnetic signal on top of the ferromagnetic signal of interest. 

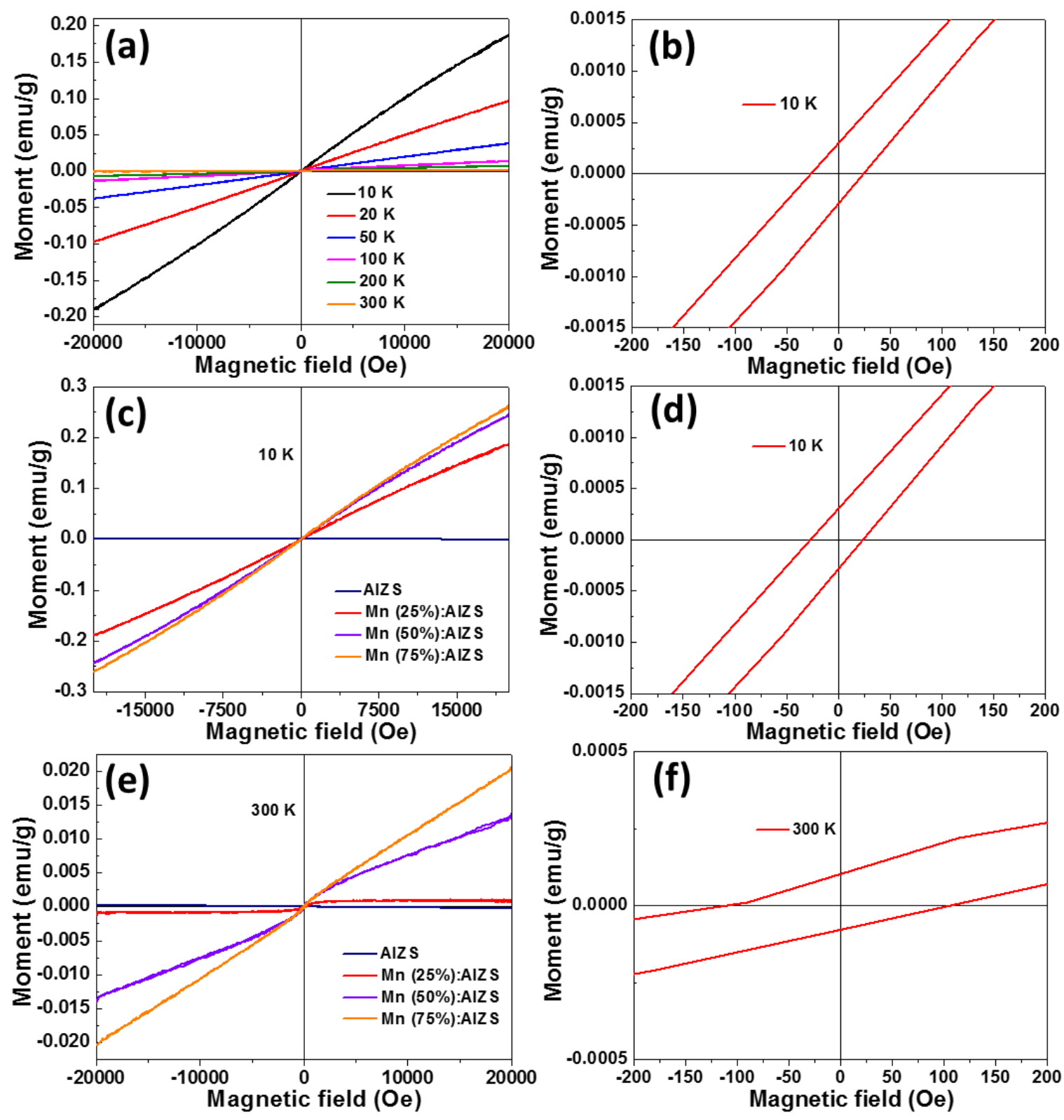

Fig. 9. (a) $M(H)$ loop curves of $M n$ (25\%):AIZS QDs at different temperatures and (b) the magnetic properties at zero field. (c) and (e) are the $M(H)$ loop curves of AIZS and Mn:AIZS QDs at $10 \mathrm{~K}$ and $300 \mathrm{~K}$, respectively. (d) and (f) describe the magnetic properties at zero field.

\section{Transfer of Mn:AIZS QDs in aqueous phase}

To demonstrate the potential of Mn:AIZS QDs for biological applications, the DDT and OAm-capped Mn:AIZS QDs were transferred into aqueous phase using the amphiphilic PMAO polymer. ${ }^{12}$ Micelles were first produced by the association of the hydrophobic alkyl chains of PMAO with those of DDT and OAm through self-assembly 
in chloroform. After evaporation of the solvent, maleic anhydride units were hydrolyzed into carboxylate functions. This hydrophilic corona allows the successful transfer of Mn:AIZS QDs in water without alteration of their optical properties. Empty micelles were removed by ultracentrifugation at $15000 \mathrm{rpm}$ and the PMAOencapsulated Mn:AIZS QDs can easily be dispersed in water, PBS or borate buffer. These colloidal dispersions can be stored for months at $4{ }^{\circ} \mathrm{C}$ indicating the high stability of the micelles. Except for the Mn (75\%):AIZS QDs, a red-shift of the PL emission is observed but the PL QYs were not significantly altered (59, 51, 40 and 11\% for AIZS and $\mathrm{Mn}$ :AIZS loaded with 25, 50 and $75 \% \mathrm{Mn}^{2+}$, respectively) (Fig. 10). The red-shift observed likely originates from the compact association of QDs in the core of the micelle in which the light emitted by the smallest nanocrystals is adsorbed by the largest ones that emit a higher wavelength like a Förster resonance energy transfer process. $^{41,42}$
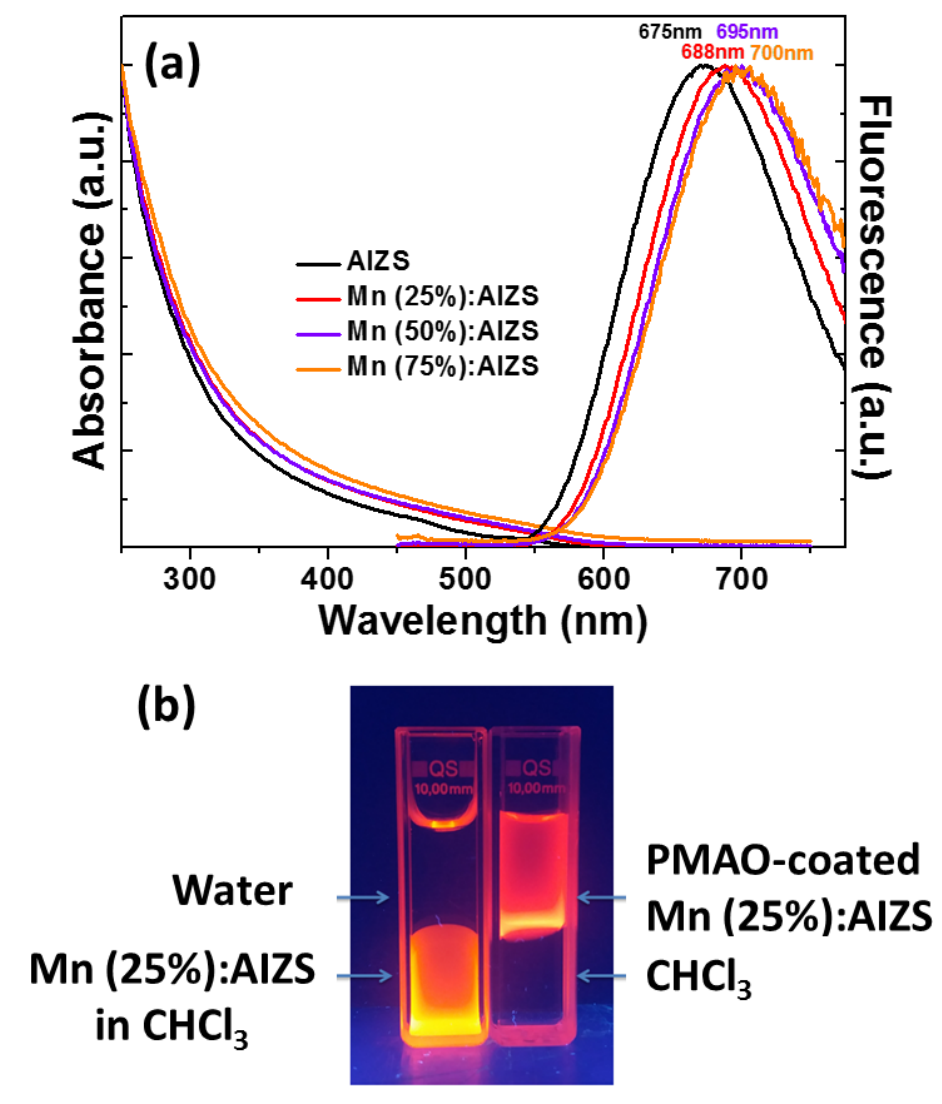
Fig. 10. (a) UV-visible and PL emission spectra of AIZS and Mn:AIZS QDs after transfer in water using the PMAO polymer and (b) digital photograph taken under UV light illumination of $\mathrm{Mn}$ (25\%):AIZS QDs before and after their transfer into water.

\section{Conclusions}

In summary, Mn:AIZS QDs were easily prepared via a one-step approach using AgOAc, $\ln (\mathrm{OAc})_{3}, \mathrm{Zn}(\mathrm{OAc})_{2}, \mathrm{Mn}(\mathrm{St})_{2}$ and thiourea as precursors DDT and OAm as capping ligands. The PL emission of Mn:AlZS originates from D-A transitions and can easily be tuned by varying the $\mathrm{Ag} / \mathrm{In} / \mathrm{Zn} / \mathrm{Mn}$ stoichiometric ratio. A red-shift of the $\mathrm{PL}$ emission is observed when increasing the $\mathrm{Mn}^{2+}$ loading likely due to the generation of $\mathrm{Mn}^{2+}$ dependent trap states. Mn:AIZS QDs were also demonstrated to exhibit ferromagnetic and paramagnetic properties. Their long PL lifetimes, which allow to differentiate their signals from the fast decaying background and biological systems PL, and their magnetic properties should allow Mn:AIZS QDs to be of high potential for bioimaging applications.

\section{Experimental}

\section{Materials}

Silver acetate ( $\geq 99.0 \%$, Sigma-Aldrich), indium acetate (99.99\%, Sigma-Aldrich), zinc acetate dihydrate ( $\geq 98 \%$, Sigma-Aldrich), thiourea ( $\geq 99.0 \%$, Sigma-Aldrich), oleylamine (OAm, technical grade, 70\%, Aldrich), 1-dodecanethiol (DDT, 98\%, Alfa Aesar), stearic acid (SA, 97\%, Acros organics), methanol ( $\geq 99.9 \%$, Carlo Erba Reagents), manganese chloride tetrahydrate ( $\geq 99.0 \%$, Sigma), tetramethylammonium hydroxide pentahydrate (TMAH, $\geq 97 \%$, Sigma), poly(maleic anhydride-alt-1octadecene) (PMAO, 30.000-50.000, Sigma-Aldrich), and chloroform ( $\geq 99 \%$, Carlo Erba Reagents) were used as received. 


\section{Synthesis of $\mathrm{Mn}(+2)$ stearate $\left(\mathrm{MnSt}_{2}\right)$}

Under a nitrogen atmosphere, stearic acid $(10 \mathrm{mmol})$ in $15 \mathrm{~mL}$ of methanol was heated to $50-60^{\circ} \mathrm{C}$ to make a homogeneous solution. After cooling the reaction mixture to room temperature, TMAH $(10 \mathrm{mmol})$ in $20 \mathrm{~mL}$ of methanol was added and the mixture was further stirred $15 \mathrm{~min}$. Next, $\mathrm{MnCl}_{2} \cdot 4 \mathrm{H}_{2} \mathrm{O}(5 \mathrm{mmol})$ in $10 \mathrm{~mL}$ of methanol was added dropwise under vigorous stirring. The white $\mathrm{MnSt}_{2}$ precipitate was collected by centrifugation, washed several times with methanol and dried under vacuum. The dried $\mathrm{MnSt}_{2}$ was stored at $4^{\circ} \mathrm{C}$ under $\mathrm{N}_{2}$ before use.

Synthesis of $\left(\mathrm{AgInS}_{2}\right)_{x}(\mathrm{ZnS})_{1-\mathrm{x}}(\mathrm{AIZS})$ and $\left.(\mathrm{AgInS})_{2}\right)_{x}(\mathrm{MnS})_{y}(\mathrm{ZnS})_{1-\mathrm{x}-\mathrm{y}}(\mathrm{Mn:AIZS})$ QDS

$\left(\mathrm{AgInS}_{2}\right)_{x}(\mathrm{ZnS})_{1-\mathrm{x}}(\mathrm{AIZS})$ and $(\mathrm{AgInS})_{\mathrm{x}}(\mathrm{MnS})_{\mathrm{y}}(\mathrm{ZnS})_{1-\mathrm{x}-\mathrm{y}}(\mathrm{Mn}: \mathrm{AIZS})$ QDs were prepared according to a facile one-step method recently described [6], with slight modifications. Green emitting nanocrystals were prepared by heating $0.02 \mathrm{mmol}$ of AgOAc, $0.02 \mathrm{mmol}$ of $\operatorname{In}(\mathrm{OAc})_{3}, 0.16 \mathrm{mmol}$ of $\mathrm{Zn}(\mathrm{OAc})_{2}$ and $0.2 \mathrm{mmol}$ of thiourea in 3 $\mathrm{mL}$ of OAm containing 2 mol\% of DDT. Red emitting nanocrystals were prepared by heating $0.06 \mathrm{mmol}$ of $\mathrm{AgOAc}, 0.06 \mathrm{mmol}$ of $\mathrm{In}(\mathrm{OAc})_{3}, 0.08 \mathrm{mmol}$ of $\mathrm{Zn}(\mathrm{OAc})_{2}$ and 0.2 mmol of thiourea in $3 \mathrm{~mL}$ of OAm containing 2 mol\% of DDT. The $\mathrm{Mn}(\mathrm{St})_{2}$ loading was varied $(25,50$ or $75 \mathrm{~mol} \%$ relative to the total amount of salts used). The precursors and ligands were mixed in a four-necked flask and the mixture stirred under an argon atmosphere until dissolution. Next, the temperature was increased to $180^{\circ} \mathrm{C}$ and maintained for $10 \mathrm{~min}$. The reaction mixture was then cooled to room temperature and centrifuged to remove large aggregates. AIZS or Mn:AIZS QDs were precipitated from the supernatant using methanol and further purified by washing with methanol and centrifugation (at least 10 times). The nanocrystals were dried under vacuum at room temperature and stored in a dark place for further characterizations.

\section{Hydro-dispersion of AIZS@DDT QDs with PMAO}

To disperse Mn:AIZS@DDT QDs in water, the amphiphilic polymer poly(maleic-alt-1octadecene) (PMAO) was used [12]. A mixture of Mn:AIZS@DDT QDs (6 mg), PMAO 
(9.4 $\mathrm{mg}$ ) and $10 \mathrm{~mL}$ of chloroform was stirred vigorously for $2 \mathrm{~h}$ at ambient temperature. Next, the solvent was removed at room temperature by using a rotary evaporator. The obtained product was dissolved in $1 \mathrm{~mL}$ of chloroform and $6 \mathrm{~mL}$ of a $0.05 \mathrm{M}$ aqueous solution of $\mathrm{NaOH}$ were added. This mixture was sonicated for $1 \mathrm{~h}$ at $50^{\circ} \mathrm{C}$ and next centrifuged for $15 \mathrm{~min}$ at $5000 \mathrm{rpm}$ to remove aggregates. Next, the supernatant was centrifuged for $30 \mathrm{~min}$ at $15000 \mathrm{rpm}$ and the pellet obtained was dispersed in a Borate Buffer solution $(\mathrm{pH}=9)$ and stored at $4^{\circ} \mathrm{C}$.

\section{Characterization}

TEM and HR-TEM images were taken by placing a drop of the particles in water onto an ultrathin carbon film-supported gold grids. XRD studies were carried out by using an X'Pert MPD diffractometer (Panalytical AXS). The samples were placed on zero background quartz sample holders and the XRD patterns were recorded at room temperature using $\mathrm{Cu} \mathrm{K}_{\alpha}$ radiation $(\lambda=0.15418 \mathrm{~nm})$. A Jeol ARM 200F microscope equipped with EDX spectrometry was used for the energy-dispersive X-ray (EDX) analysis. The actual compositions of $\mathrm{Mn}$ :AIZS QDs was also determined using an inductively coupled plasma-optical emission spectrometer (ICP-OES) (Thermo). The samples were prepared by digestion of the dried QDs with $\mathrm{HCl} / \mathrm{HNO}_{3} 3: 1(\mathrm{v} / \mathrm{v})$ for 12 $h$, followed by dilution with Milli-Q water. TGA was conducted under $\mathrm{O}_{2}$ atmosphere from room temperature to $800^{\circ} \mathrm{C}$ at a heating rate of $10^{\circ} \mathrm{C} / \mathrm{min}$ using a TGA/DSC1 STAR equipment (Mettler-Toledo). X-band EPR spectra were recorded in nonsaturating conditions on a Bruker ELEXSYS 500 spectrometer equipped with an Oxford instrument continuous-flow liquid-helium cryostat and a temperature control system. Typical conditions were : $5 \mathrm{G}$ amplitude modulation, $9.402 \mathrm{GHz}$, microwave power : $2.52 \mathrm{~mW}$.

All the optical measurements were performed at room temperature $\left(20 \pm 1^{\circ} \mathrm{C}\right)$ under ambient conditions. FT-IR spectra were recorded on a Bruker ALPHA spectrometer. Absorption spectra were obtained with a Thermo Scientific Evolution 220 UV-visible spectrophotometer, while PL spectra were measured on a Horiba Fluoromax-4 Jobin Yvon spectrofluorimeter. PL spectra were spectrally corrected and PL QYs were determined relative to Rhodamine $6 \mathrm{G}$ in ethanol (PL QY $=94 \%$ ). For the PL excitation 
measurements, a Horiba Jobin Yvon Fluorolog spectrofluorimeter equipped with a Xe lamp source was used. The PL signal was analyzed by a monochromator equipped with a 150 grooves/mm grating and by a CCD detector cooled at $200 \mathrm{~K}$. For the time resolved photoluminescence (TR-PL) experiments, the QDs were pumped by the 355 $\mathrm{nm}$ line of a frequency-tripled YAG (yttrium aluminium garnet): Nd laser. The laser pulse frequency, energy and duration were typically equal to $10 \mathrm{~Hz}, 50 \mu \mathrm{J}$ and $10 \mathrm{~ns}$, respectively. The PL signal was analyzed by a monochromator equipped with a 600 grooves/mm grating and by a photomultiplier tube cooled at $190 \mathrm{~K}$. The rise time of the detector is equal to around 3 ns.

Magnetic properties were characterized with vibrating sample magnetometry (VSM) at temperatures of 10 and $300 \mathrm{~K}$, with applied magnetic field $(H)$ up to $\pm 9 \mathrm{~T}$. The magnetic moment values are reported in electromagnetic units (emu) per mass unit of sample.

\section{Conflicts of interest}

There are no conflicts to declare.

\section{Acknowledgements}

The authors thank the Bolashak International Scholarship of JSC "Center for International Programs" for financial support.

\section{Notes and references}

1 H. Zhong, Z. Bai and B. Zou, J. Phys. Chem. Lett., 2012, 3, 3167-3175.

2 D. Wang, W. Zheng, C. Hao, Q. Peng and Y. Li, Chem. Commun., 2008, 2556-2558.

3 S. Liu and X. Su, RSC Adv., 2014, 4, 43415-43428.

4 G. Xu, S. Zeng, B. Zhang, M. T. Swihart, K. -T. Yong and P. N. Prasad, Chem. Rev., 2016, $116,12234-12327$.

5 W. M. Girma, M. Z. Fahmi, A. Parmadi, M. A. Abati and J. -Y. Chang, J. Mater. Chem. B, 2017, 5, 6193-6216. 
6 T. Kameyama, T. Takahashi, T. Machida, Y. Kamiya, T. Yamamoto, S. Kuwabata and T. Torimoto, J. Phys. Chem. C, 2015, 119, 24740-24749.

7 H. Abdullah and D. -H. Huo, ACS Appl. Mater. Interfaces, 2015, 7, 26941-26951.

8 D.B. Choi, S. Kim, H.C. Yoon, M. Ko, H. Yang and Y. R. Do, J. Mater. Chem. C, 2017, 5, 953-959.

9 R. Boonsin, A. Barros, F. Donat, D. Boyer, G. Chadeyron, R. Schneider, P. Boutinaud and R. Mahiou, ACS Photonics, 2018, 5, 462-470.

10 M. Jagadeeswaravao, A. Swarnkar, G. B. Markad and A. Nag, J. Phys. Chem. C, 2016, 120, 19461-19469.

11J. Song, C. Ma, W. Zhang, S. Yang, S. Wang, L. Lv, L. Zhu, R. Xia and X. Xu, J. Mater. Chem. B, 2016, 4, 7909-7918.

12 M. Michalska, A. Florczak, H. Dams-Kozlowska, J. Gapinski, S. Jurga and R. Schneider, Acta Biomater., 2016, 35, 293-304.

13 W. -W. Xiong, G. -H. Yang, X. -C. Wu and J. -J. Zhu, J. Mater. Chem. B, 2013, 1, 41604165.

$14 \mathrm{H}$. Shinchi, M. Wakao, N. Nagata, M. Sakamoto, E. Mochizuki, T. Hematou, S. Kuwabata and Y. Suda, Bioconjugate Chem., 2014, 25, 286-295.

15 L. Wang, X. Kang and D. Pan, Inorg. Chem., 2017, 56, 6122-6130.

16 B. Mao, C. -H. Chuang, J. Wang and C. Burda, J. Phys. Chem. C, 2011, 115, 8945-8954.

17Y. Hamanaka, T. Ogawa and M. Tsuzuki, J. Phys. Chem. C, 2011, 115, 1786-1792.

18 M. J. Rao, T. Shibata, S. Chattopadhyay and A. Nag, J. Phys. Chem. Lett., 2014, 5, 167173.

19B. Mao, C. -H. Chuang, C. McCleese, J. Zhu and C. Burda, J. Phys. Chem. C, 2014, 118, 13883-13889.

20S. Jeong, H. C. Yoon, N. S. Han, J. H. Oh, S. M. Park, B. K. Min, Y. R. Do and J. K. Song, J. Phys. Chem. C, 2017, 121, 3149-3155.

210. Stroyuk, A. Raevskaya, F. Spranger, O. Selyshchev, V. Dzhagan, S. Schulze, D. R. T. Zahn and A. Eychmüller, J. Phys. Chem. C, 2018, 122, 13648-13658.

22 K. Hattori, K. Akamatou and N. Kamegashira, J. Appl. Phys., 1992, 71, 3414-3418.

23S. H. You, K. J. Hong, C. J. Youn, T. S. Jeong, J. D. Moon, H. S. Kim and J. S. Park, J. Appl. Phys., 2001, 90, 3894-3898.

24G. Manna, S. Jana, R. Bose and N. Pradhan, J. Phys. Chem. Lett., 2012, 3, 2528-2534. 
25X. Tang, Z. Zu, L. Bian, J. Du, W. Chen, X. Zeng, M. Wen, Z. Zang and J. Xue, Mater. Des., 2016, 91, 256-261.

26P. Zhou, X. Zhang, L. Li, X. Liu, L. Yuan and X. Zhang, Opt. Mater. Express, 2015, 5, 2069-2080.

27B. Huang, Q. Dai, N. Zhuo, Q. Jiang, F. Shi, H. Wang, H. Zhang, C. Liao, Y. Cui and J. Zhang, J. Appl. Phys., 2014, 116, 094303.

28 T. Takahashi, A. Kudo, S. Kuwabata, A. Ishikawa, H. Ishihara, Y. Tsuboi and T. Torimoto, J. Phys. Chem. C, 2013, 117, 2511-2520.

29 M. Dai, S. Ogawa, T. Kameyama, K. -I. Okazaki, A. Kudo, S. Kuwabata, Y. Tsuboi and T. Torimoto, J. Mater. Chem., 2012, 22, 12851-12858.

30A. Aboulaich, M. Geszke, L. Balan, J. Ghanbaja, G. Medjahdi and R. Schneider, Inorg. Chem., 2010, 49, 10940-10948.

31 R. Zhou, S. Sun, C. Li, L. Wu, X. Hou and P. Wu, ACS Appl. Mater. Interfaces, 2018, 10, 34060-34067.

32 F. Aldeek, L. Balan, G. Medjahdi, T. Roques-Carmes, J. -P. Malval, C. Mustin, J. Ghanbaja and R. Schneider, J. Phys. Chem. C, 2009, 113, 19458-19467.

33X. S. Tang, W. B. A. Ho and J. M. Xue, J. Phys. Chem. C, 2012, 116, 9769-9773.

34A. Albert manoharan, R. Chandramohan, R. David prabu, S. Valanarasu, V. Ganesh, Mohd Shkir, A. Kathalingam and S. AlFaify, J. Mol. Struct., 2018, 1171, 388-395.

35S. Ravi and F. Winfred Shashikanth, Mater. Lett., 2015, 141, 132-134.

36Sh. Zhu, Ch. Chen, Zh. Li, J. Magn. Magn. Mater., 2019, 471, 370-380.

37 N. Sharma, A. Gaur and R.K. Kotnala, J. Magn. Magn. Mater., 2015, 377, 183-189.

38 Ch. Jing, Y. Jiang, W. Bai, J. Chu and A. Liu, J. Magn. Magn. Mater., 2010, 322, $2395-$ 2400.

39R. Zhou, Sh. -K. Sun, Ch. Li, L. Wu, X. Hou and P. Wu, ACS Appl. Mater. Interfaces, $2018,10,34060-34067$.

40 J. Amighian, E. Karimzadeh and M. Mozaffari, J. Magn. Magn. Mater., 2013, 332, 157162.

41 M. Booth, R. Peel, R. Partanen, N. Hondow, V. Vasilia, L. J. C. Jeuken and K. Critchley, RSC Adv., 2013, 3, 20559-20566.

42 S. Chen, M. Ahmadiantehrani, N. G. Publicover, K. W. Hunter and X. Zhu, RSC Adv., 2015, 5, 60612-60620. 